\title{
WPŁYW WYBRANYCH MIKRODODATKÓW NA PRZEWODNICTWO CIEPLNE ORAZ MIKROSTRUKTURĘ POWIERZCHNI MODYFIKOWANYCH GIPSÓW
}

\author{
Karol Prałat ${ }^{\bowtie}$, Wojciech Kubissa, Roman Jaskulski, Justyna Ciemnicka, \\ Sławomir Pilarczyk
}

Wydział Budownictwa, Mechaniki i Petrochemii, Politechnika Warszawska, Płock

\begin{abstract}
STRESZCZENIE
Prezentowana praca zawiera dane eksperymentalne dotyczące wpływu mikrododatków na wartość przewodnictwa cieplnego gipsu. W badaniach wykorzystano: mikrosfery, aerożel oraz polimer hydroksyetyloetylocelulozę (HEMC). Polimer i aerożel zastosowano jako dodatek w ułamku wagowym 1\%, a mikrosfery w ułamku wagowym $10 \%$ w stosunku do zawartości gipsu. Do pomiaru przewodnictwa cieplnego wykorzystano metodę niestacjonarną z układem doświadczalnym Isomet 2114. Zaobserwowano spadek przewodności cieplnej i gęstości wraz z dodatkiem mikroproduktów ze względu na modyfikacje struktury produktu gipsowego. Wykonano ponadto zdjęcia mikroskopowe przełomów modyfikowanych gipsów.
\end{abstract}

Słowa kluczowe: przewodnictwo cieplne, mikrododatki, mikrostruktura powierzchni, nanomateriały

\section{WSTĘP}

Gips jest materiałem budowlanym o bardzo szerokim zastosowaniu. Jest postrzegany jako bezpieczny, użyteczny i przyjazny dla środowiska. W budownictwie gips służy do wykonywania: tynków wewnętrznych, dekoracyjnych detali architektonicznych, posągów, płyt gipsowo-kartonowych, podłóg i bloków konstrukcyjnych, a także zapraw i klejów. Ta szeroka użyteczność wynika z uniwersalnych właściwości fizycznych tego materiału. Elementy gipsowe są całkowicie bezwonne, przyjazne dla środowiska naturalnego i ognioodporne. Zapewniają one również izolację termiczną i akustyczną. Dodatkowo gips ma naturalny mechanizm do higrotermicznej równowagi środowiska wewnętrznego (Heim, Mrowiec, Pralat i Mucha,
2018). Obecnie tynki gipsowe stały się materiałem do wykańczania wnętrz w wielu krajach. Doskonała wydajność, atrakcyjny wygląd, łatwe zastosowanie i jego zdrowotny wpływ na warunki życia sprawiły, że gips jest najpopularniejszym materiałem wykończeniowym (Duggal, 1998; Khalil, Tawfik, Hegazy i El-Shahat, 2013).

W budownictwie rozwiązania konstrukcyjno-materiałowo-instalacyjne bardzo często zmierzają do zastosowania niekonwencjonalnych metod pozyskiwania energii zawartych $\mathrm{w}$ środowisku naturalnym, na przykład poprzez wykorzystanie pompy ciepła oraz niekonwencjonalnych metod jej magazynowania $\mathrm{w}$ gruncie, złożach kamiennych, substancjach o niskiej temperaturze przemian fazowych. Nowoczesne rozwiązania mogą obejmować: sys-

${ }^{凶}$ Karol.Pralat@pw.edu.pl 
temy odzyskiwania ciepła, sterowanie warunkami mikroklimatu środowiska wewnętrznego, pomiary zużycia energii, nieklasyczne konstrukcje okien o małych wartościach współczynnika przenikania ciepła. Obecnie bardzo szeroką dziedziną nauki w ramach nowoczesnych, prośrodowiskowych rozwiązań materiałowych jest poszukiwanie izolacji oraz kompozytów budowlanych o małych wartościach współczynnika przewodnictwa cieplnego.

Uzyskiwanie małych wartości współczynnika przewodnictwa cieplnego materiałów izolacyjnych dokonuje się obecnie za pomoca dodatku lub wbudowania $\mathrm{w}$ ich strukturę materiałów zmiennofazowych (PCM), które są w stanie absorbować, akumulować i uwalniać dużą ilość energii w zakresie temperatury przemiany fazowej. W trakcie pochłaniania energii temperatura materiału nie ulega zmianie. Wykorzystywane sa zarówno związki nieorganiczne (uwodnione sole), jak i organiczne (parafiny, kwasy tłuszczowe, ciecze jonowe).

Właściwości materiałowe, mechaniczne i termiczne czystego gipsu i jego składników są bardzo dobrze znane i opisane w literaturze (Yu i Brouwers, 2012; Adrien, Meille, Tadier, Maire i Sasaki, 2016). Jako tradycyjny niemodyfikowany produkt budowlany ma on przewodność cieplną wahającą się w zakresie od 0,3 do $1,0 \mathrm{~W} \cdot \mathrm{m}^{-1} \cdot \mathrm{K}^{-1}$.

Nowym sposobem zmniejszania wartości współczynnika przewodnictwa cieplnego jest dodatek do materiałów budowlanych (w tym gipsów), mikroi nanocząstek, które wbudowane w strukturę substancji pozwalają na otrzymanie kompozytów o nowych interesujących właściwościach termicznych.

Gips można modyfikować różnymi dodatkami chemicznymi, które powodują różnice we właściwościach kompozytów. Najczęściej są to: przyspieszacze, opóźniacze, włókna celulozowe i włókna szklane, wermikulit, aerożele, środki redukujące wodę, głównie polimery i kopolimery, mikrosfery (Arikan i Sobolev, 2002; Khalil i in., 2013; Strzałkowski i Garbalińska 2016; Chen, Ng, Li i Kwan, 2017; Maghsoudi i Motahari, 2017). Zastosowane chemiczne dodatki zmieniają różne właściwości fizyczne (w tym cieplne), a szczególnie przewodnictwo. $Z$ tego powodu wszelkie modyfikacje gipsu wpływają na jego użyteczne właściwości i zastosowanie. Wpływ róż- nych mikro- i nanododatków na przewodność cieplną gipsu nie jest jeszcze dobrze poznany.

Znajomość wartości przewodności cieplnej $(\lambda)$ wielu materiałów budowlanych jest bardzo ważna w praktyce inżynierskiej i badaniach eksperymentalnych. Wraz z określonym ciepłem właściwym $\left(C_{p}\right)$, gęstością $(\rho)$ i dyfuzyjnością cieplną $(a)$ jest to jeden z najważniejszych parametrów substancji fizycznych i chemicznych. Powyższe właściwości są ze sobą wzajemnie powiązane:

$a=\frac{\lambda}{C_{p} \cdot \rho}$

W prezentowanym artykule zastosowano trzy rodzaje mikrododatków do gipsu: polimer hydroksyetyloetyloceluloze (HEMC), aerożel oraz mikrosfery. Niestacjonarna metoda pomiarów pozwoliła na określenie właściwości termicznych kompozytów, w szczególności przewodnictwa, w ciagu pierwszych 35 dni twardnienia próbek. Podczas badań wykonano dodatkowo pomiary gęstości próbek oraz mikroskopowe zdjęcia zmodyfikowanych powierzchni gipsów.

\section{MATERIA I METODY}

W prezentowanym eksperymencie wykonano cztery próbki gipsowe - wzorcową (bez mikrododatków) oraz próbki z dodatkiem mikrosfer, polimeru oraz aerożelu. W kompozytach zastosowano wagowo $10 \%$ mikrosfer oraz $1 \%$ aerożelu i $1 \%$ polimeru w stosunku do gipsu. We wszystkich próbach przyjęto stosunek wody do gipsu na stałym poziomie $\mathrm{w} / \mathrm{g}=0,75$.

Aerożele są jednymi z najlepszych materiałów termoizolacyjnych dostępnych obecnie na rynku. Są one ognioodporne i mają wartości przewodności cieplnej na poziomie zaledwie $0,012-0,018 \mathrm{~W} \cdot \mathrm{m}^{-1} \cdot \mathrm{K}^{-1}$. Mikrosfery są lekkimi, cienkościennymi pustymi kulkami, które są produktami ubocznymi spalania sproszkowanego węgla w elektrowniach cieplnych. Ze względu na swoje właściwości są potencjalnie interesującym wypełniaczem i mogą być stosowane do produkcji kompozytów na bazie cementu (Pichór, 2009). Hydroksyetylometyloceluloza jest niejonowym polimerem o dużej lepkości i nietoksyczności bardzo dobrze rozpuszczalna w wodzie. Polimer HEMC jest jednym 
z eterów celulozy i znajduje szerokie zastosowanie w budownictwie. Może być on stosowany do modyfikowania materiałów budowlanych wykonanych na bazie wszelkich zapraw takich jak cement lub gips.

Materiałem wyjściowym w badaniach przewodności cieplnej był naturalny proszek gipsowy (Nida Gips) powszechnie dostępny na rynku i spełniający wymagania standardowe. Ilość siarczanu wapnia $\left(\mathrm{CaSO}_{4}\right)$ w gipsie wynosiła $91 \%$.

Wielkość mikrocząstek dodawanych do gipsu wynosiły odpowiednio: 150-250 $\mu \mathrm{m}$ dla polimeru,

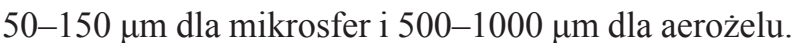
Cząstki aerożelu w swojej strukturze zawierały liczne pory o średnicy do $20 \mathrm{~nm}$.

Modyfikowane komponenty zostały wykonane poprzez wymieszanie czystego gipsu z wodnym roztworem mikrododatku z zastosowaniem wolnoobrotowego mieszadła przez $1 \mathrm{~min} \mathrm{w}$ temperaturze $20^{\circ} \mathrm{C}$, a następnie zostały umieszczone $\mathrm{w}$ formach $\mathrm{w}$ kształcie sześcianów o wymiarach $100 \times 100 \times 100 \mathrm{~mm}$.

Badanie przewodnictwa cieplnego przeprowadzono za pomocą urządzenia pomiarowego Isomet 2114 (rys. 1). Przyrząd ten jest przenośnym urządzeniem wykorzystującym metodę niestacjonarną pomiaru, przeznaczonym do bezpośredniego wyznaczania parametrów przepływu ciepła. Jest on wyposażony w szeroki zakres pomiarowy i jest przeznaczony do badania materiałów izolacyjnych, budowlanych, tworzyw sztucznych, szkła czy minerałów. Zakres pomiarowy zależy od zastosowanej sondy i wynosi od 0,015 do $6,0 \mathrm{~W} \cdot \mathrm{m}^{-1} \cdot \mathrm{K}^{-1}$. Przyrząd wyposażony jest w dwa opcjonalne typy sond pomiarowych: sondy igłowe dla materiałów miękkich lub sondy powierzchniowe dla materiałów twardych. Dane pomiarowe mogą być zapamiętywane $\mathrm{w}$ wewnętrznej pamięci urządzenia lub przesłane do komputera. Pomiar za pomocą urządzenia Isomet polega na analizie odpowiedzi temperatury badanego materiału na impulsy przepływu ciepła. Podczas eksperymentu znana ilość ciepła wytwarzana przez źródło powoduje falę cieplną, propagującą prostopadle do próbki. Wzrost temperatury źródła zmienia się liniowo z logarytmem czasu. Zależność tę można wykorzystać bezpośrednio do obliczenia przewodności cieplnej próbki (Kušnerová i in., 2013; Glinicki, Jaskulski, Pichór Dąbrowski i Sobczak, 2015; Strzałkowski i Garbalińska, 2016).

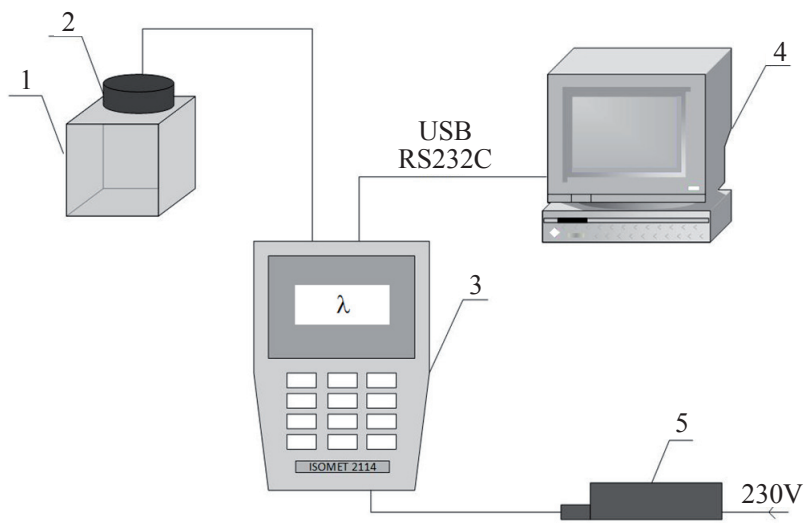

Rys. 1. Stanowisko do pomiaru przewodnictwa cieplnego ( $\lambda$ ): 1 - badana próbka, 2 - sonda powierzchniowa, 3 - mikroprocesorowy przyrząd Isomet, 4 - komputer, 5 - zasilacz prądu stałego

Fig. 1. Experimental set up to measure thermal conductivity $(\lambda): 1$ - tested sample, 2 - surface probe, 3 - microprocessor-controlled Isomet instrument, 4 - PC computer, 5 - AC/DC power supply

Badania przewodnictwa cieplnego dokonywano dla każdej z czterech próbek po 1, 3, 7, 14, 21, 28 dniach doświadczenia. Próbki kondycjonowano w temperaturze $20-22^{\circ} \mathrm{C}$ i wilgotności $52 \pm 2 \%$. Po 28 dniach próbki gipsu osiągnęły stan wyschnięcia na powietrzu. Następnie dodatkowo próbki suszono w temperaturze $65^{\circ} \mathrm{C}$ przez 7 dni, badając po tym czasie wartość przewodnictwa cieplnego. Za każdym razem próbki były ważone, co umożliwiało wyznaczenie gęstości badanych kostek gipsowych.

Po zakończeniu badań cieplnych wykonano zdjęcia badanych kompozytów za pomocą laboratoryjnego mikroskopu stereoskopowego, przy zastosowanym powiększeniu 100× i z użyciem kamery Moticam, co umożliwiło obserwację szczegółów o wymiarze do $20 \mu \mathrm{m}$.

\section{WYNIKI}

Właściwości bloku gipsowego bez mikrododatków charakteryzowały się gęstością na poziomie $1026 \mathrm{~kg} \cdot \mathrm{m}^{-3}$ i przewodnością cieplną o wartości $0,3113 \mathrm{~W} \cdot \mathrm{m}^{-1} \cdot \mathrm{K}^{-1}$ po 28 dniach suszenia do stanu suchej masy. Po czasie tygodniowego suszenia w suszarce przewodność zmniejszyła się nieznacznie do wartości $0,3014 \mathrm{~W} \cdot \mathrm{m}^{-1} \cdot \mathrm{K}^{-1}$. 
Uzyskane po 35 dniach trwania eksperymentu wartości przewodnictwa cieplnego oraz wartości wskaźników zmienności zamieszczono w tabeli 1.

Próbki gipsowe modyfikowane mikrododatkami wykazały mniejsze wartości przewodnictwa w porównaniu z czystym gipsem. Wartość współczynnika przewodnictwa cieplnego próbki gipsowej z zawartością polimeru była o ponad $15 \%$ mniejsza, a z zawartością aerożelu oraz mikrosfer odpowiednio o ponad 8 oraz $7 \%$ mniejsza w porównaniu z próbą wzorcową.
Przebieg zmienności współczynnika przewodzenia ciepła w czasie trwania eksperymentu wszystkich czterech próbek gipsowych zestawiono na rysunku 2 .

Podczas trwania eksperymentu badano gęstość próbek. Po czasie 35 dni, po całkowitym wysuszeniu, obliczono dodatkowo wartości porowatości gipsów. Wyniki obliczeń zestawiono w tabeli 2, a zmiany współczynnika przewodzenia ciepła w funkcji gęstości na rysunku 3.

Podczas pierwszych kilku dni hydratacji gipsu badane próbki zawierały wodę, która nie była używana

Tabela 1. Wartości przewodnictwa cieplnego oraz współczynnika zmienności czystego gipsu oraz gipsu z dodatkiem polimeru, aerożelu oraz mikrosfer po 35 dniach

Table 1. Values of thermal conductivity, specific and coefficient of variation of the pure gypsum and gypsum with additives polymer, aerogel and microspheres after 35 days

\begin{tabular}{lcccc}
\hline \multirow{2}{*}{$\begin{array}{l}\text { Parametr } \\
\text { Parameter }\end{array}$} & \multicolumn{3}{c}{ Building materials - Materiały budowlane } \\
\cline { 2 - 4 } & $\begin{array}{c}\text { gips } \\
\text { gypsum }\end{array}$ & $\begin{array}{c}\text { gips polimer } \\
\text { gypsum and polymer }\end{array}$ & $\begin{array}{c}\text { gips i mikrosfery } \\
\text { gypsum and microspheres }\end{array}$ & $\begin{array}{c}\text { gips i aerożel } \\
\text { gypsum and aerogel }\end{array}$ \\
\hline $\begin{array}{l}\text { Przewodnictwo cieplne } \\
\begin{array}{l}\text { Thermal conductivity } \\
\lambda\left[\mathrm{W} \cdot \mathrm{m}^{-1} \cdot \mathrm{K}^{-1}\right]\end{array}\end{array}$ & 0,3014 & 0,2542 & 0,2767 \\
\hline $\begin{array}{l}\text { Współczynnik zmienności } \\
\text { Coefficient of variation } \\
V[\%]\end{array}$ & 1,55 & 2,70 & 3,15 & 2,44 \\
\hline
\end{tabular}

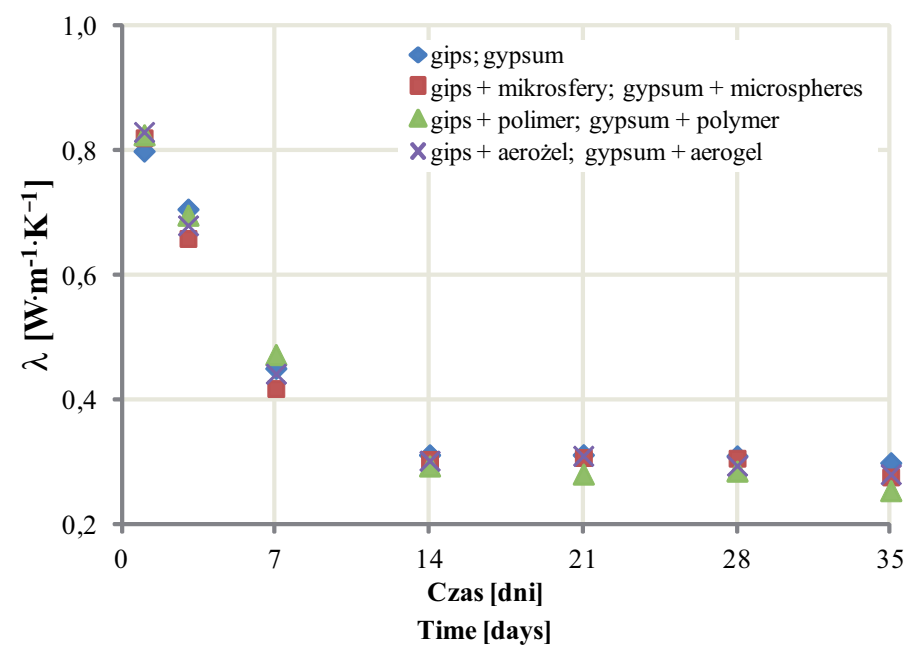

Rys. 2. Zmiany przewodności cieplnej próbek gipsowych podczas procesu twardnienia czystego gipsu z różnymi dodatkami w czasie 35 dni

Fig. 2. Thermal conductivity changes of gypsum specimens during hardening process for pure gypsum with different additives for 35 days 
Prałat, K., Kubissa, W., Jaskulski, R., Ciemnicka, J., Pilarczyk, S. (2019). Wpływ wybranych mikrododatków na przewodnictwo cieplne oraz mikrostrukturę powierzchni modyfikowanych gipsów. Acta Sci. Pol. Architectura 18 (1), 69-75, DOI: 10.22630/ASPA.2019.18.1.8

Tabela 2. Gęstość i porowatość kompozytów gipsowych po 35 dniach

Table 2. Density and porosity of gypsum composites after 35 days

\begin{tabular}{lcccc}
\hline \multirow{2}{*}{$\begin{array}{l}\text { Parametr } \\
\text { Parameter }\end{array}$} & \multicolumn{4}{c}{ Materiały budowlane - Building materials } \\
\cline { 2 - 4 } & $\begin{array}{c}\text { gips } \\
\text { gypsum }\end{array}$ & $\begin{array}{c}\text { gips i polimer } \\
\text { gypsum and polymer }\end{array}$ & $\begin{array}{c}\text { gips i mikrosfery } \\
\text { gypsum and microspheres }\end{array}$ & $\begin{array}{c}\text { gips i aerożel } \\
\text { gypsum and aerogel }\end{array}$ \\
\hline $\begin{array}{l}\text { Gęstość }- \text { Density } \\
\rho\left[\mathrm{kg} \cdot \mathrm{m}^{-3}\right]\end{array}$ & 997 & 941 & 922 & 919 \\
\hline $\begin{array}{l}\text { Porowatość - Porosity } \\
k_{p}[\%]\end{array}$ & 57,7 & 60,0 & 60,7 & 61,0 \\
\hline
\end{tabular}

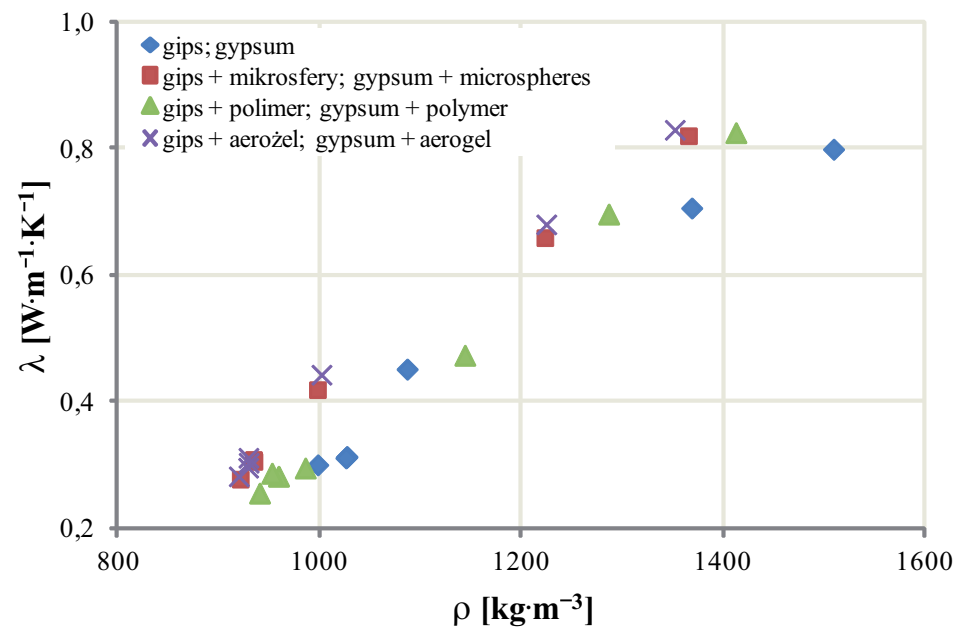

Rys. 3. Współczynnik przewodzenia ciepła w funkcji gęstości próbek gipsowych o różnej zawartości wilgoci i różnych mikrododatków

Fig. 3. Thermal conductivity coefficient versus density of gypsum specimens with different moisture contents and different micro additives

Tabela 3. Stałe $A$ oraz $B$ równania (2)

Table 3. Constants $A$ and $B$ of equation (2)

\begin{tabular}{ccccc}
\hline \multirow{2}{*}{$\begin{array}{c}\text { Stała } \\
\text { Constant }\end{array}$} & $\begin{array}{c}\text { Materiały budowlane - Building materials } \\
\text { gypsum }\end{array}$ & $\begin{array}{c}\text { gips i polimer } \\
\text { gypsum and polymer }\end{array}$ & $\begin{array}{c}\text { gips i mikrosfery } \\
\text { gypsum and microspheres }\end{array}$ & $\begin{array}{c}\text { gips i aerożel } \\
\text { gypsum and aerogel }\end{array}$ \\
\hline$A$ & 0,0010 & 0,0012 & 0,0012 & 0,0013 \\
\hline$B$ & 0,7176 & 0,8886 & 0,8090 & 0,8520 \\
\hline$R^{2}$ & 0,9782 & 0,9943 & 0,9947 & 0,9918 \\
\hline
\end{tabular}



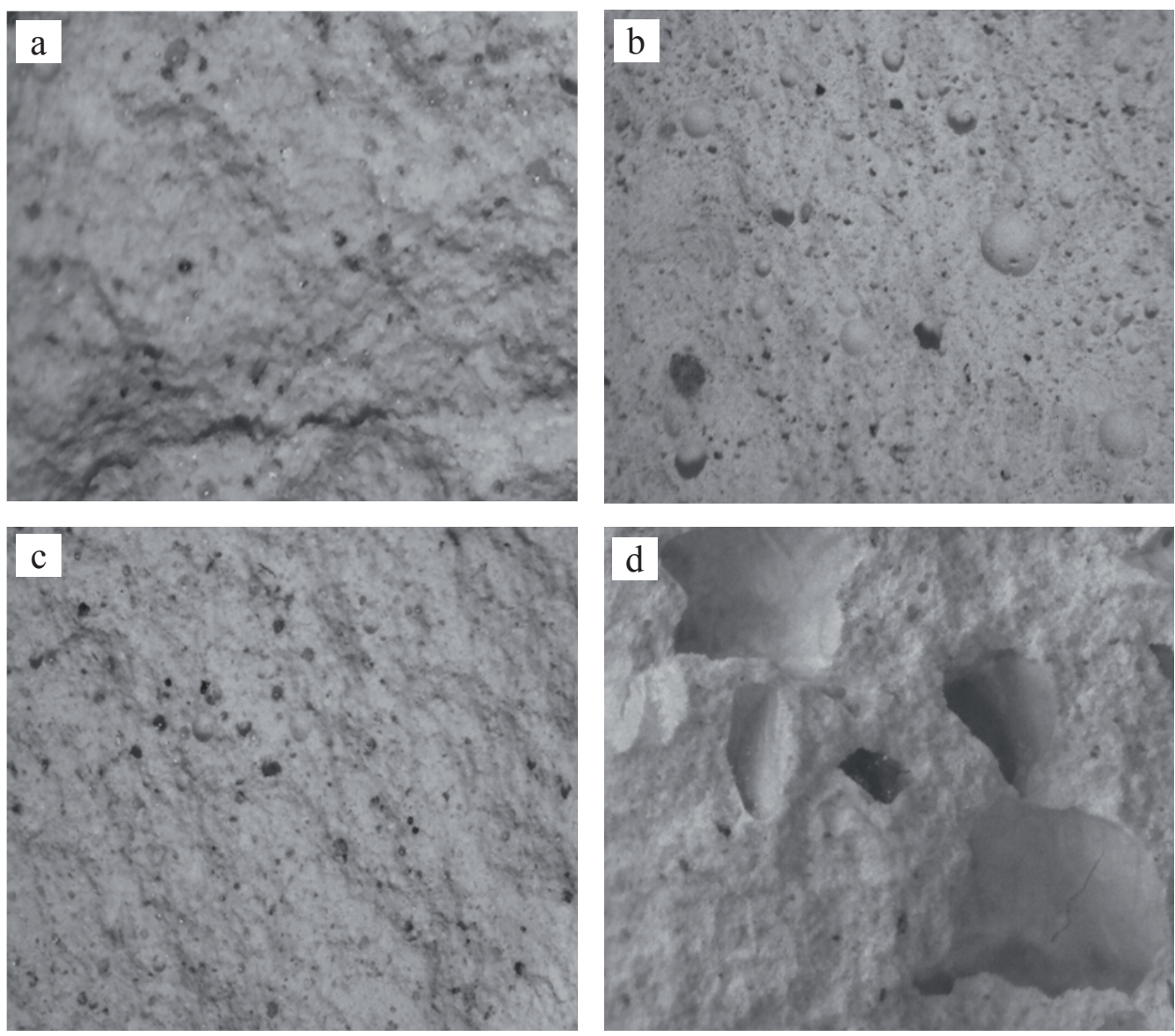

Rys. 4. Zdjęcia mikroskopowe badanych próbek: a - gips, b - gips + mikrosfery, $\mathrm{c}-$ gips + polimer, $\mathrm{d}-$ gips + aerożel

Fig. 4. Microscopic photos of the tested specimens: $a-$ gypsum, $b-$ gypsum + microspheres, $c-$ gypsum + polymer, $\mathrm{d}-$ gypsum + aerogel

w procesach chemicznych i która odparowywała następnie podczas twardnienia. Duża ilość wody odpowiadała większej gęstości.

Próbki z zawartością mikrododatków charakteryzowały się mniejszą gęstością i jednocześnie mniejszym przewodnictwem cieplnym. Dla wszystkich badanych próbek gipsowych zaproponowano uogólnioną zależność (2), a stałe równania umieszczono w tabeli 3.

$$
\lambda=A \cdot \rho-B
$$

Po 35 dniach trwania eksperymentu, w których badano właściwości cieplne oraz gęstość próbek, wykonano dodatkowo zdjęcia mikroskopowe przełomów modyfikowanych gipsów (rys. 4). Na rysunku 4b za- uważalne są ziarna mikrosfer, a na rysunku $4 \mathrm{~d}$ nierozpuszczalne w gipsie cząstki aerożelu. Cząstki polimeru, które są bardzo dobrze rozpuszczalne w wodzie, nie są widoczne na zdjęciach z mikroskopu stereoskopowego (rys. 4c). Obecność mikrododatków o bardzo małych wartościach przewodnictwa cieplnego w strukturze gipsu wpłynęła znacząco na wartość współczynnika przewodnictwa cieplnego całego kompozytu.

\section{WNIOSKI}

1. Mikrododatki zmieniają strukturę nowych kompozytów gipsowych, co znajduje odzwierciedlenie w gęstości i przewodności cieplnej końcowych produktów. Zmianę strukturalną potwierdzają również zdjęcia mikroskopowe przełomów gipsowych. 
2. W procesie twardnienia nadmiar niekrystalicznej wody paruje z porów, prowadząc do spadku gęstości i przewodności cieplnej próbek. Wzrost porowatości doprowadził do spadku przewodności cieplnej.

3. Zawartość gipsu z polimerem zmniejszyła o ponad $15 \%$ przewodność cieplną w porównaniu z próbką bez HEMC. Gips z zawartością aerożelu i mikrosfer zmniejszył odpowiednio o ponad 8 i 7\% wartość przewodnictwa cieplnego $\mathrm{w}$ porównaniu z czystym gipsem.

4. Analizowane nowe kompozyty gipsowe moga stać się materiałami przyjaznymi dla środowiska naturalnego, o lepszych właściwościach izolacyjnych.

\section{PIŚMIENNICTWO}

Adrien, J., Meille, S., Tadier, S., Maire E. i Sasaki, L. (2016). In-situ X-ray tomographic monitoring of gypsum plaster setting. Cement and Concrete Research, 82, 107-116.

Arikan, M. i Sobolev, K. (2002). The optimization of a gypsum-based composite material. Cement and Concrete Research, 32 (11), 1725-1728.

Chen, J. J., Ng, P. L., Li, L. G. i Kwan, A. K. H. (2017). Production of high-performance concrete by addition of fly ash microsphere and condensed silica fume. Procedia Engineering, 172, 165-171.

Duggal, S. K. (1998). Building Materials. Rotterdam: A.A. Balkema Publishers.

Heim, D., Mrowiec, A., Pralat, K.I. i Mucha, M. (2018). Influence of Tylose MH1000 Content on Gypsum Thermal Conductivity. Journal of Materials in Civil Engineering, 30 (3), 1-8.
Glinicki, M. A., Jaskulski, R., Pichór, W., Dąbrowski, M. i Sobczak, M. (2015). Investigation of thermal properties of shielding concrete. W Proceeding of International Symposium "Brittle Matrix Composites 11" (strony 371-380). Warszawa: Institute of Fundamental Technological Research.

Khalil, A. A., Tawfik, A., Hegazy, A. A. i El-Shahat, M. F. (2013). Effect of different forms of silica on the physical and mechanical properties of gypsum plaster composites. Materiales de Construcción, 63 (312), 529-537.

Kušnerová, M., Valíček, J., Harničárová, M., Hryniewicz, T., Rokosz, K., Palková, Z. i Bendová, M. (2013). A proposal for simplifying the method of evaluation of uncertainties in measurement results. Measurement Science Review, 13 (1), 1-6.

Maghsoudi, K. i Motahari, S. (2018). Mechanical, thermal, and hydrophobic properties of silica aerogel-epoxy composites. Journal of Applied Polymer Science, 135 (3), 1-9.

Pichór, W. (2009). Properties of fiber reinforced cement composites with cenospheres from coal ash. W Proceeding of International Symposium "Brittle Matrix Composites 9" (strony 245-254). Warszawa: Institute of Fundamental Technological Research.

Strzałkowski, J. i Garbalińska, H. (2016). Thermal and strength properties of lightweight concretes with the addition of aerogel particles. Advances in Cement Research, 28 (9), 567-575.

Yu, Q. L. i Brouwers, H. J. H. (2012). Thermal properties and microstructure of gypsum board and its dehydration products: a theoretical and experimental investigation. Fire and Materials, 36 (7), 575-589.

\title{
INFLUENCE OF SELECTED MICRO ADDITIVES ON THERMAL CONDUCTIVITY AND SURFACE MICROSTRUCTURE OF MODIFIED GYPSUM
}

\begin{abstract}
The presented work includes experimental data on the influence of micromaterials on thermal conductivity of gypsum. In this research used: microspheres, aerogel and polymer hydroxyethyl methyl cellulose. The polymer and the aerogel are used as an additive in the weight fraction, up to $1 \%$ and the microspheres in the weight fraction, up to $10 \%$ of gypsum. For the purpose of measuring of thermal conductivity, a non-stationary method with the Isomet 2114 experimental setup was used. A decrease of thermal conductivity and density with added microproducts were observed because of structure modifications of the gypsum product. Additional microscopic images of the fractures of modified gypsum were made.
\end{abstract}

Key words: thermal conductivity, micro additives, surface microstructure, nanomaterials 
